\title{
Destruction of Silica Fiber Materials under Shock Wave and Radiation Loadings
}

\author{
V.P. Efremov ${ }^{1 *}$, A.V. Utkin ${ }^{1,2}$ \\ ${ }^{1}$ Joint Institute for High Temperatures of Russian Academy of Sciences, Izhorskaya St., 13, Bd.2, Moscow, 125412, Russia; \\ ${ }^{2}$ Institute of Problems of Chemical Physics, Russian Academy of Sciences, \\ 1, Semenov avenue, Chernogolovka, Moscow Region, 142432, Russia \\ * Corresponding author. Tel.: +7 49548509 63. E-mail: dr.efremov@gmail.com
}

\begin{abstract}
The disturbance of the light conductivity in optical fiber transporting intense laser radiation leads to the occurrence of brightly illuminated laser plasma region. Plasma begins to move towards radiation, irreversibly damaging the optical fiber. Depending on the intensity of the laser energy, different rates of propagation of damage along the optical fibers towards the radiation are possible. This is either "combustion" of optical fibers, or "optical detonation". Both of these processes "combustion" and "optical detonation" of optical fibers - destroy the light conductivity of silica fibers along the entire length. The rate of propagation of "combustion" depends on the energy density and is several meters per second. The detonation-like mode of destruction extends with velocity of several kilometers per second. Shock-wave data of silica fiber materials are necessary for modeling of the of such destruction process. In this paper the experimental study of propagation of the shock wave front in the materials of the optical fibers core in explosive experiments was carried out for the first time. For study of the detonation-like mode of a laser discharge propagation, experimental fibers were produced by the Fiber Optics Research Center of the Russian Academy of Sciences (FORC RAS) and an available industrial communication fiber (SMF-28e single-mode fiber from Corning). In the shock wave experiment, a two-wave mode of the propagation of the shock wave is confirmed. Anomalous compressibility behind the front of the shock wave was found in the materials of the optical fiber. The decrease in the sound velocity was about one $\mathrm{km} / \mathrm{s}$.
\end{abstract}

\section{Keywords}

Laser-supported detonation; single-mode fiber; laser plasma.

\section{Introduction}

Intensive laser radiation can lead to the emergence plasma and propagation of damage in optical fibers. Depending on the intensity of the laser, different velocities of propagation of damage along the optical fibers towards the radiation are possible. This is either "combustion" of optical fibers or "optical detonation" $[1,2]$. Both of these processes - "combustion" and "optical detonation" of optical fibers destroy the light conductivity of silica fibers along the entire length. The rate of propagation of "combustion" depends on the energy density and is several meters per second.

The detonation-like mode of destruction extends at velocity of several kilometers per second. The analysis of the limiting possible velocity for such a mode is important both for the safety of optical lines based on silica fibers and for the construction of high-power lasers on fiber optics. In addition, the physical explosion of the optical fiber in the transport reservoirs can lead to the initiation of explosive combustible of gas mixtures (secondary explosion).

In the experiments, we recorded the following parameters:

- the velocity of propagation of the process along the fiber - by streak camera;

- the zone of pressure, plasma glow and the beginning of destruction - by fast camera from the exposure time of $2 \mathrm{~ns}$;

- the acoustic precursor (compression wave) - by fast camera from the exposure time of $2 \mathrm{~ns}$ and using the technique of crossed polarizers.

The results of dynamic measurements were published in our early papers [1-6].

The interpretation of experimental results and the construction of numerical models were constrained by 
the lack of data on the properties of materials used for the fiber core. In particular, there were no data on the shock-wave properties and the structure of the compression wave front.

In this paper, for the first time, an experimental study has been carried out of the features of the propagation of the shock wave front in materials of optical fibers.

\section{Experimental}

For study of the detonation-like mode of a laser discharge propagation, experimental fibers were produced by the Fiber Optics Research Center of the Russian Academy of Sciences (FORC RAS) and an available industrial communication fiber (SMF-28e single-mode fiber from Corning).

Most optical cables are assembled from SMF-28e. This fiber has a stepped profile of the refractive index due to the introduction of the $\mathrm{GeO}_{2}$ additive $(\sim 3 \mathrm{~mol} \%)$ into the core; it has a core diameter of $8.2 \mu \mathrm{m}$ and a quartz shell diameter of $125 \mu \mathrm{m}$. The optical fiber is coated with a polymer shell with a diameter of $240 \mu \mathrm{m}$.
The microstructure of damages of fibers after optical detonation was studied with a scanning electron microscope.

The optical fiber parameters are given in Table 1. F1 and F2 are model optical fibers. F2 is a model optical fiber, close in parameters to the Corning SMF28 industrial fiber.

The experiments were carried out on samples prepared from the blanks for optical fibers in FORC RAS (Fig. 1a). The photos of the samples are shown in Fig. $1 b$ and Fig. 1c. The samples were made in the form of disks with a diameter of $12 \mathrm{~mm}$, a thickness of $2 \mathrm{~mm}$ and a core of $4 \mathrm{~mm}$. The average density of the produced disks was $\rho_{0}=2.27 \mathrm{~g} / \mathrm{cm}^{3}$.

The mass velocity was recorded by an interferometer (VISAR) through a water window. The aluminum foil with $7 \mu \mathrm{m}$ thick was glued on samples to reflect laser radiation of interferometer. The explosive device used in the experiments is show in Fig. 2. The experimental assembly in the experiments is shown in Fig. 3. The photo of the assembly sequence of the experimental setup is shown in Fig. 4.

Parameters of optical silica-based fibers

Table 1

\begin{tabular}{lccc}
\hline \multicolumn{1}{c}{ Fiber } & $\mathrm{F} 1$ & $\mathrm{~F} 2$ & $\mathrm{~F}$ ( Corning SMF-28 \\
\hline Quartz cower diameter, $\mu$ & 600 & 125 & 125 \\
Core diameter, um & 9.5 & 7.7 & 8.2 \\
Refractive index difference (RID) & 0.006 & 0.013 & 0.005 \\
Composition $\mathrm{SiO}_{2}: \mathrm{GeO}_{2}: \mathrm{Al}_{2} \mathrm{O}_{3}$ & $97: 1: 2$ & $89: 11: 0$ & $96.5: 3.5: 0$ \\
$\begin{array}{l}\text { Mode field diameter at the laser } \\
\text { wavelength } 1064 \mathrm{~nm} \text {, um }\end{array}$ & 10.5 & 6.13 & 8.9 \\
\hline
\end{tabular}

For F2 fiber with a large decline in the refractive index (RID) in the center - an effective step index; F3 fiber - Corning SMF-28 $8^{\mathrm{TM}}$

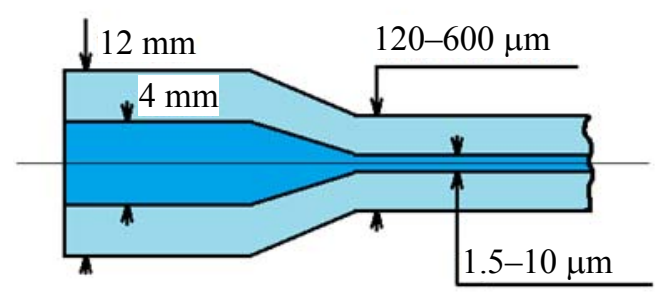

a)

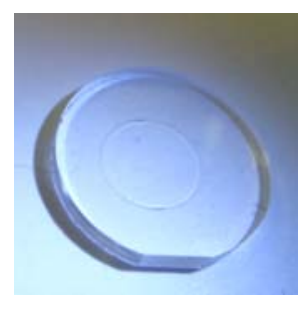

b)

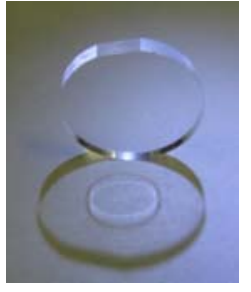

c)

Fig. 1. Photos of samples

(Samples were made in the form of disks with a diameter of $12 \mathrm{~mm}$, a thickness of $2 \mathrm{~mm}$ and a core of $4 \mathrm{~mm}$. The average density of the produced disks $\rho_{0}=2.27 \mathrm{~g} / \mathrm{cm}^{3}$ ) 


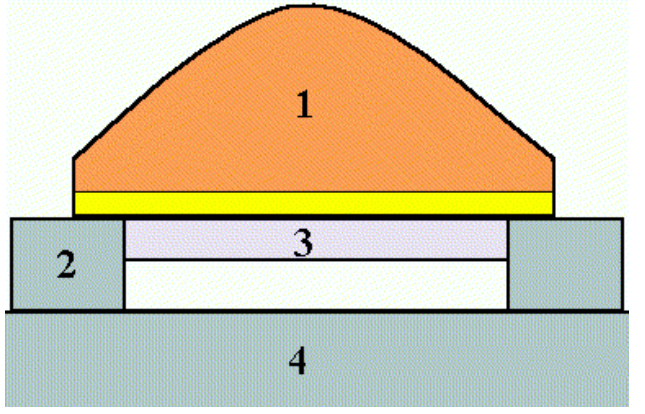

Fig. 2. Explosive device:

1 - explosive lens, A-IX-1/ paraffine, $\varnothing=100 \mathrm{~mm} ; 2$ - focusing ring, steel, $\varnothing_{\mathrm{ext}}=150 \mathrm{~mm}, h=16 \mathrm{~mm} ; 3$ - impactor, D16T,

$\varnothing=90 \mathrm{~mm}, h=7 \mathrm{~mm} ; 4$ - screen, impactor velocity $1.13 \mathrm{~km} / \mathrm{s}$

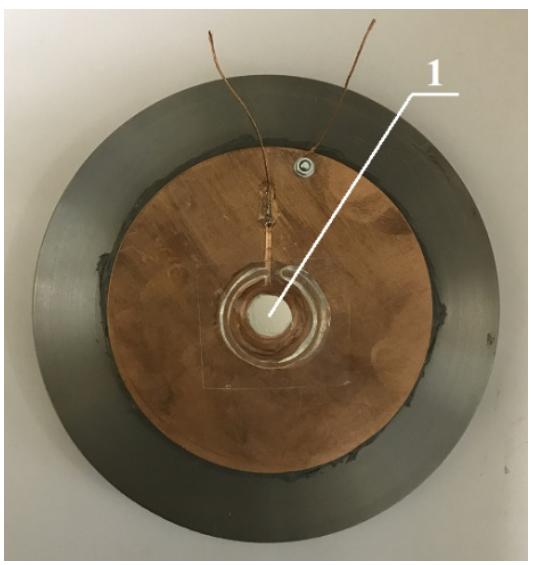

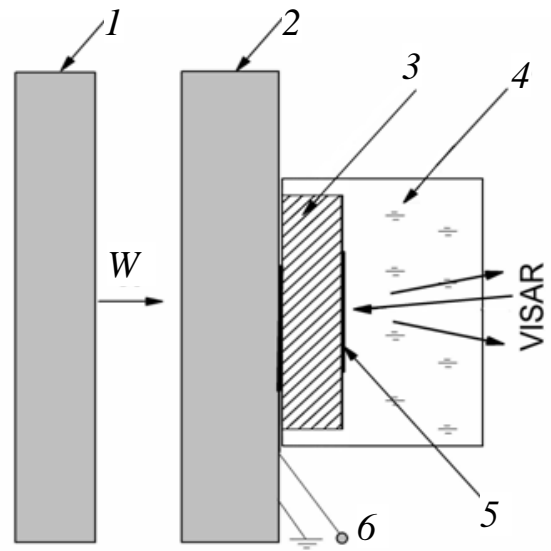

Fig. 3. Experimental assembly:

1 - aluminum impactor; 2 - screen; 3 - sample; 4 - water; 5 - aluminum foil; 6 - polarization sensor

Fig. 4. Photo of experimental assembly (1 - sample of the fiber core)

The front of the shock wave has a distinctly expressed two-wave structure: a wave with amplitude of about $400 \mathrm{~m} / \mathrm{s}$ and a diffuse front followed by a second wave with a sharp front (Fig. 5): $D_{1}$ - velocity of the first wave (short arrow); $D_{2}-$ velocity of the second wave (long arrow).

If two wave configurations are realized, then the waves should scatter. This is precisely what is observed when the thickness of the samples is changed by a factor of two. The first wave is blurred as it spreads, which is due to the anomalous compressibility of fused quartz at a pressure below 2.5-3.0 GPa.

Fig. 6 shows the front parts of the velocity profiles in the $t / h$ coordinates, where $h$ is the thickness of the sample. In these experiments, the compression stress did not exceed the value of the dynamic elastic limit of fused quartz, which is equal to $8.8 \mathrm{GPa}[8,9]$. A good coincidence of the wave profiles in these coordinates indicates the self-similarity of the compression wave and makes it possible to find the character of the decrease in the sound velocity with increasing pressure in the region of anomalous compression.

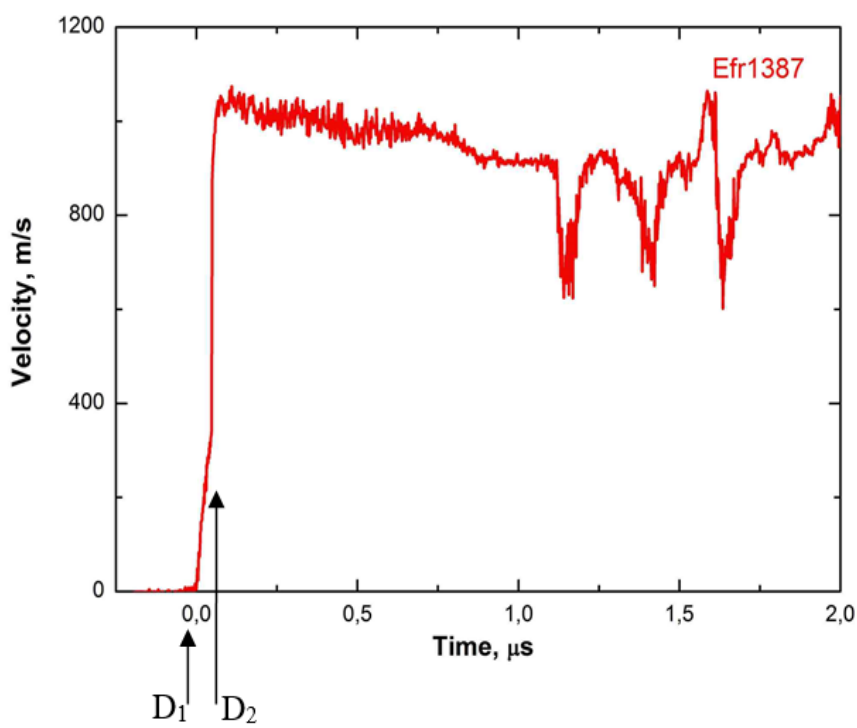

Fig. 5. Mass velocity at the quartz-water interface (Aluminum impactor $h=7 \mathrm{~mm}, W=1.13 \mathrm{~km} / \mathrm{s}$; aluminum screen $h=4 \mathrm{~mm}$; sample $h=2 \mathrm{~mm}$. The shock wave velocity $D_{1}=5.47 \mathrm{~km} / \mathrm{s}, D_{2}=4.73 \mathrm{~km} / \mathrm{s}$ ) 


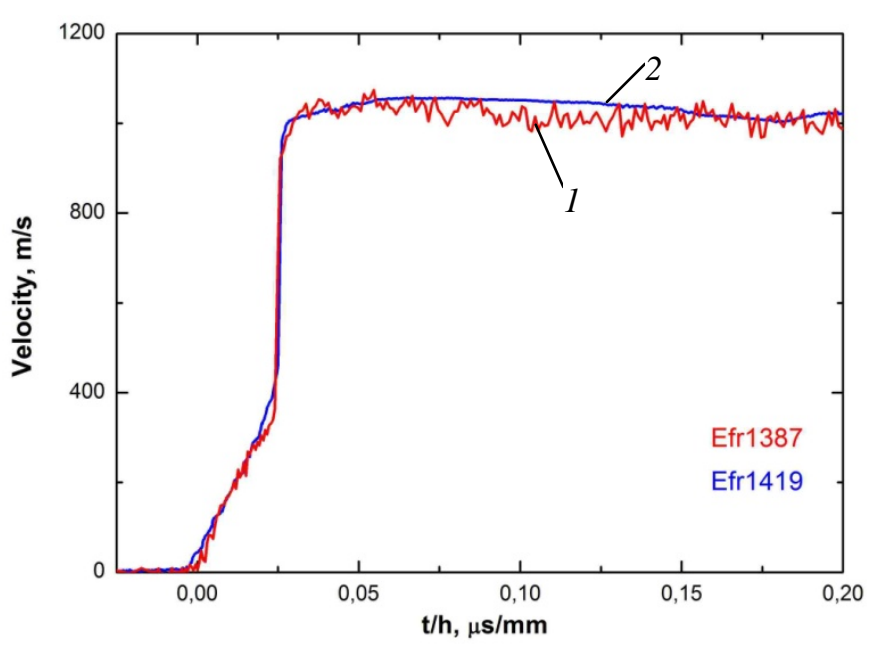

Fig. 6. Aluminum impactor $h=7 \mathrm{~mm}, W=1.13 \mathrm{~km} / \mathrm{s}$; aluminum screen $h=4 \mathrm{~mm}$; sample $2 \mathrm{~mm}($ red 1) and $4 \mathrm{~mm}$ (blue 2)

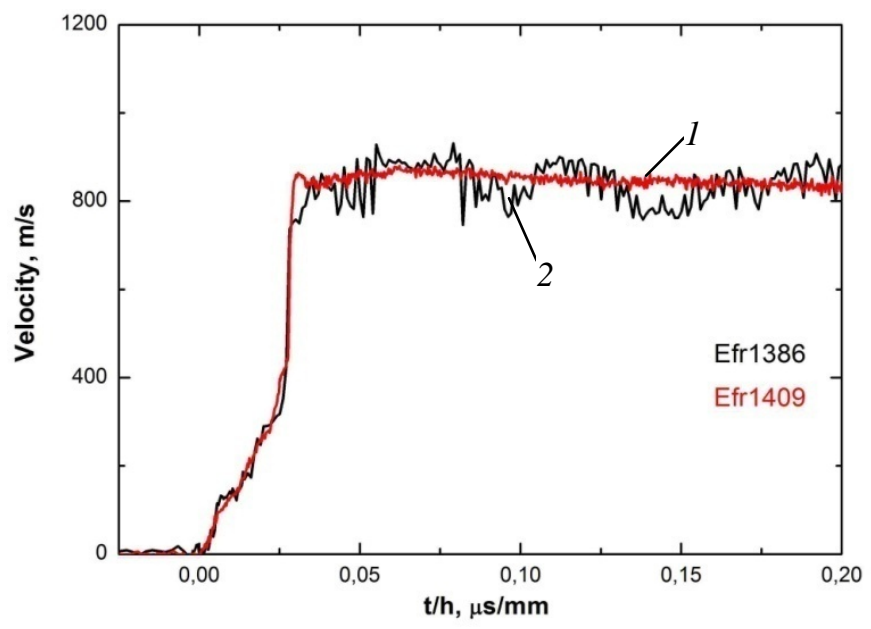

Fig. 7. Aluminum impactor $h=7 \mathrm{~mm}, W=1.13 \mathrm{~km} / \mathrm{s}$; copper screen $h=5.5 \mathrm{~mm}$; sample $2 \mathrm{~mm}$ (red 1) and $4 \mathrm{~mm}$ (black 2)

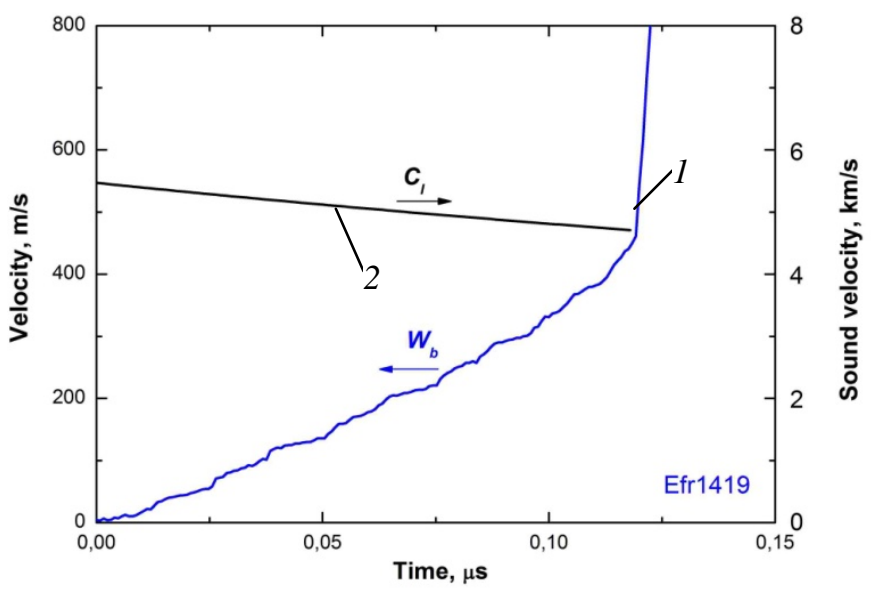

Fig. 8. Aluminum impactor $h=7 \mathrm{~mm}, W=1.13 \mathrm{~km} / \mathrm{s}$; aluminum screen $h=4$ MM; sample thickness $4 \mathrm{~mm}$; velocity profile (blue 1) and sound velocity (black 2) in the region of anomalous compression
The similarly way, in Fig. 7 in the $t / h$ coordinates, the front part of the velocity profiles is constructed at a lower shock compression pressure (copper screen). In spite of the strongly oscillating velocity profile 1409 , in this case a fairly good coincidence of the wave profiles is also observed. Fig. 8 shows the velocity profiles (blue line 1) and the sound velocity (black line 2) in the region of anomalous compression.

\section{Results and discussion}

The propagation of the destruction process is caused by the laser plasma in the volume of the material and by a sharp increase in the absorption coefficient of the laser radiation in the layers of material nearby with laser plasma zone. The burning mode with a wave propagation velocity of about $1 \mathrm{~m} / \mathrm{s}$ is achievable even at a laser radiation intensity (wavelength $1 \mu \mathrm{m}$ ) in the core of the fiber of the order of $0.1 \mathrm{~W} / \mu \mathrm{m}^{2}$, the detonation mode occurs at a velocity of about $\sim 3 \mathrm{~km} / \mathrm{s}$ at intensities above $\sim 20 \mathrm{~W} / \mathrm{cm}^{2}$. The nature of the dependence of the wave velocity on the absorbed laser energy is different in these two modes. In both cases, there is a strong heating of the core material of the fiber, which radiates as a black body. The temperatures of laser heating of the matter can reach $10^{4} \mathrm{~K}$. However, the rates of matter heating $K_{t}$ in the wave fronts differ by three orders of magnitude.

The terms "combustion" and "optical detonation" introduced from chemical media are used here quite arbitrarily. In contrast to the release of internal energy in the front during ordinary combustion and detonation, transition of the transported energy of laser radiation occurs to thermal energy in transparent media.

During combustion, the displacement of the absorption front occurs with a thermal wave, during detonation - with a shock wave. The application of the term and the theory of combustion to optical combustion was shown in [7].

A strong evidence of application of the term "optical detonation" to the process under investigation is hampered by the complex nature of the flow in the front and the dependence of the energy release process on the radius.

The driver of damage to the optical fiber is the formation of laser plasma in the core of the optical fiber, the temperature of which can reach $10^{4} \mathrm{~K}$. The channel filled with gas remains after cooling in the core. In the combustion mode, the cavity moves along with the plasma front; depending on the conditions in the core, there can be both a continuous channel and a periodic sequence of bubbles; its formation occurs 


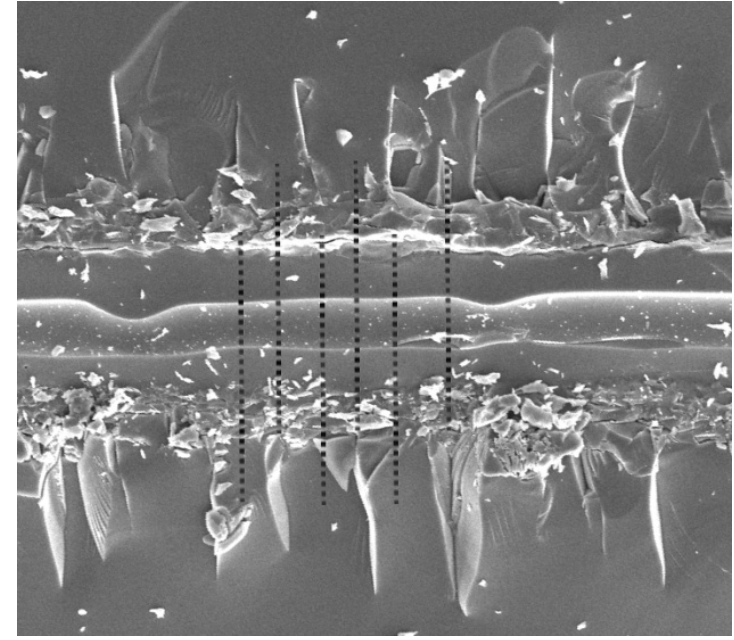

Fig. 9. Photograph of the stored fiber. Detonation region (Dashed lines indicate the position of the axial planes in which the radial cracks lie. The destruction wave moved from right to left)

under conditions of a flux of matter along the fiber axis and the hydrodynamic instability of the liquid glass-gas interface. In high-speed mode, the plasma front moves only about $200 \mathrm{~ns}$ (for our experimental conditions), which is much less than the cooling time of the substance. In this case, the resulting cavity can be described as a central channel extending from the start position to the stopping point.

A fundamental difference in the destruction of optical fibers in the fast mode is the formation of cracks in the quartz shell, occurring at the shell-core interface. The pressure near the plasma front is higher than the strength of the material. The character of the crack formation is varied in different sections of the fast mode. In addition, the cracks formed in the quartz shell cause splitting of the fiber in the longitudinal direction. This allowed us to gain access to the core region of the saved samples, previously removing the polymer coating of the optical fiber by heating on a metal plate with a temperature of about $500{ }^{\circ} \mathrm{C}$ during 30 seconds. In the same experiments, where the polymer coating was previously removed, the sample disintegrated into several parts during the passage of the destruction wave. The saved sample of the optical fiber is shown in Fig. 9. It can be seen that along the axis there is an empty channel surrounded by the melted zone, the area of intense crushing and radial cracks.

\section{Conclusion}

Earlier the dynamics of the laser destruction of optical fibers were studied [3]. Two wave profiles of the shock wave were detected. These studies were carried out using a fast camera. After the laser destruction process with the help of a scanning electron microscope, the character of the destruction of the saved fragments was studied.

For the first time the experimental study of the propagation of the shock wave front in the materials of the core of optical fibers was carried out in explosive experiments. Two wave profiles of the shock wave were confirmed. Anomalous compressibility behind the front of the shock wave was found. In this area, the decrease in the sound velocity was about one $\mathrm{km} / \mathrm{s}$.

\section{Acknowledgements}

The authors are grateful to S.L. Semenov, Director of Fiber Optics Research Center of the Russian Academy of Sciences, for supporting the research.

The research was funded by the Program of Fundamental Research of the Presidium of the Russian Academy of Sciences (Program Code I.31P).

\section{References}

1. Dianov E.M., Fortov V.E., Bufetov I.A., Efremov V.P., Frolov A.A., Schelev M.Y. and Lozovoi V.I. Detonation-like mode of the destruction of optical fibers under intense laser radiation J. Exp. Theo. Phys. Lett., 2006, vol. 83, issue 2, pp. 75-78.

2. Efremov V.P., Frolov A.A., Dianov E.M., Bufetov I.A., Fortov V.E., Dynamics of laser-induced shock wave in silica Archives of Metallurgy and Materials, 2014, vol. 59, issue 4, pp. 1599-1603.

3. Efremov V.P., Fortov V.E., Frolov A.A. Damage of silica-based optical fibers in laser supported detonation Journal of Physics: XXX International Conference on Interaction of Intense Energy Fluxes with Matter, 2015, vol. 653, p. 012-013.

4. Efremov V.P., Ivanov M.F., Kiverin A.D., Yakovenko I.S. Mechanisms of direct detonation initiation via thermal explosion of radiatively heated gas-particles layer Results in Physics, 2015, vol. 5, pp. 290-296.

5. Efremov V.P., Frolov A. A., and Fortov V.E. Laser Supported Detonation in Silica-based Optical Fibers // 25th ICDERS August 2-7, Leeds, UK, 2015, pp. 1-5.

6. Efremov V.P. [Combustion and detonation of transparent dielectrics with external energy supply], Sbornik materialov Mezhdunarodnoj konferencii «SVS-50», priurochennoj k 50-letnemu yubileyu nauchnogo otkrytiya metoda samorasprostranyayushchegosya vysokotemperaturnogo sinteza (SVS). Chernogolovka, ISMAN, 2017, pp. 99-101. (Rus)

7. Gorbachenko V.I., Dovzhenko A.Yu., Merzhanov A.G., Rumanov E.N., Fortov V.E., Yachmeneva O.E. [Limits of propagation of a slow wave of optical breakdown in an optical fiber]. Doklady akademii nauk, 2010, vol. 433, issue 5, pp. 618-620.Wackerle J. Shock-Wave Compression of Quartz J. Appl. Phys, 1962, vol. 33, p. 922. (Rus)

8. Wackerle J. Shock-Wave Compression of Quartz, J. Appl. Phys, 1962, vol. 33, p. 922.

9. Barker L.M., Hollenbach R.E. Shock-Wave Studies of PMMA, Fused Silica, and Sapphire J. Appl. Phys, 1970, vol. 41, p. 4208. 